http://jmscr.igmpublication.org/home/ ISSN (e)-2347-176x ISSN (p) 2455-0450

crossref DOI: https://dx.doi.org/10.18535/jmscr/v8i4.60

Journal Of Medical Science And Clinical Research

\title{
Axenfeld Rieger Syndrome: A Case Report
}

\author{
Authors \\ Kashyap Anurag Kumar ${ }^{1}$, Sharan Sarang Pani $^{2}$, Singh Hemendra ${ }^{3}$ \\ Srivastav Tanmay ${ }^{4}$, Mishra Deepak ${ }^{5}$ \\ 1,2 Junior Resident,Regional Institute of Ophthalmology, Banaras Hindu University,Varanasi, India \\ ${ }^{3,4}$ Senior Resident, Regional Institute of Ophthalmology, Banaras Hindu University, Varanasi, India \\ ${ }^{5}$ Assistant Professor, Regional Institute of Ophthalmology, Banaras Hindu University, Varanasi, India
}

\begin{abstract}
Axenfeld Rieger Syndrome is a rare autosomal dominant multisystem disorder. In this particular disorder there is ocular, craniofacial and dental anomalies. Ocular abnormalities include correctopia, polycoria and in late childhood or adolescence about half of affected individuals develop glaucoma. In our particular case, A 11 year old male consulted in our department for watering and discharge from both eyes and diminution of vision since childhood. On general examination he had right sided head tilt, hypertelorism and flat nasal bridge. On ocular examination his visual acuity was finger count at $3 m$ in both eyes which did not improved with pin hole. Bitot spot was present in both eyes along with polycoria and correctopia in anterior segment. On fundus examination generalized tessellation was present in right eye and both eye had glaucomatous optic atrophy with vertical Cup: Disk ratio of 0.80.9. He was diagnosed as a case of Axenfeld Reiger Syndrome with early onset glaucomatous optic atrophy. He was prescribed Intra ocular pressure lowering drugs and his pressures were well controlled on medication.
\end{abstract}

Keywords: axenfeld reiger syndrome, correctopia, polycoria, bitot spot.

\section{Introduction}

Axenfeld Rieger syndrome is the umbrella term for a spectrum of disorders featuring bilateral developmental ocular anomalies caused by defective neural crest cell related processes during fetal development.

An abnormal endothelial cell membrane has been identified on anterior segment structures in some patients.

It includes

i. Axenfeld anomaly (posterior embryotoxon)

ii. Rieger anomaly

iii. Rieger syndrome
The key implication of the syndrome is a $50 \%$ risk of glaucoma.

Cases can be sporadic or can have autosomal dominant inheritance with variable expressivity but very high penetrance.

There is no gender predilection.

Associated variants in several different genes have been found, including mutation in PITX2 on ch.4q25, FOXC1 on 6p25, PAX6 on 11p13 and FOXO1A on 13q14 and RIEG2; that is, different genetic abnormalities can give a similar clinical picture. $^{[1,2]}$

Axenfeld anomaly is characterised by posterior embryotoxon $^{[3]}$ (a prominent and anteriorly 


\section{JMSCR Vol||08||Issue||04||Page 322-325||A pril}

displaced schwalbe line) with attached strands of peripheral iris, the latter best viewed with gonioscopy.

Rieger anomaly presenting features are similar to that of iridocornea endothelial (ICE) syndrome:

Posterior embryotoxon

Iris stromal hypoplasia

Ectropion uveae

Corectopia and full thickness iris defects.

Rieger syndrome ${ }^{[4,5]}$ is characterised by Rieger anomaly with extraocular malformations like

Dental anomalies: hypodontia (few teeth) and microdontia (small teeth).

Facial anomalies: maxillary hypoplasia, broad nasal bridge, telecanthus and hypertelorism.

Paraumbilical skin and hypospadias.

\section{Case Report}

This study was a case report in a tertiary hospital (Regional Institute of Ophthalmology, Banaras Hindu University). Informed consent was taken and the study was approved by institute's ethical committee.

A 11 year boy presented to us with complaints of watering and intermittent whitish discharge from both eyes since birth and recurrent body lesion with itching from past 7 year. His mother was attendant and her reliability was satisfactory.

\section{Examination Findings}

\section{General Examination}

- Right head tilt

- Hypertelorism with broad nasal bridge (figure 1a).

- Dental anomalies (Figure 1b).

\section{Ocular Examination}

- Visual acuity of both eyes was finger count at $3 \mathrm{~m}$.

- Both eyes bitot spots, polycoria with corectopia (Figure 2).

- Mild Iris stromal hypoplasia.

- Sluggishly reactive pupil.

- Fundus examination revealed both eyes disc palor with vertical $\mathrm{C}: \mathrm{D}$ ratio of 0.8 and generalised tessellations in right eye (figure 3).

- Both eyes intraocular pressure was $16 \mathrm{mmHg}$.

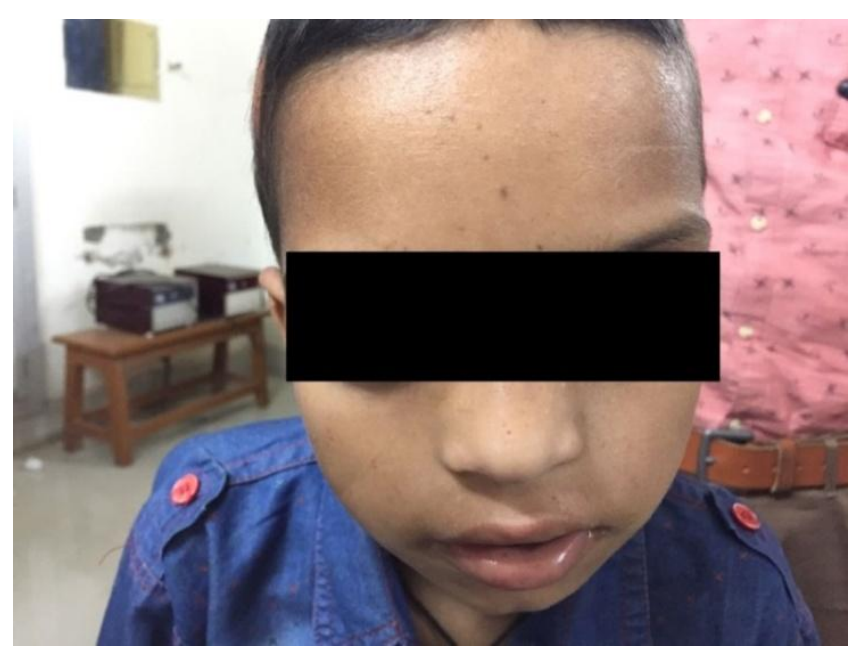

Figure 1a showing broad nasal bridge



Figure 1b showing dental anomaly

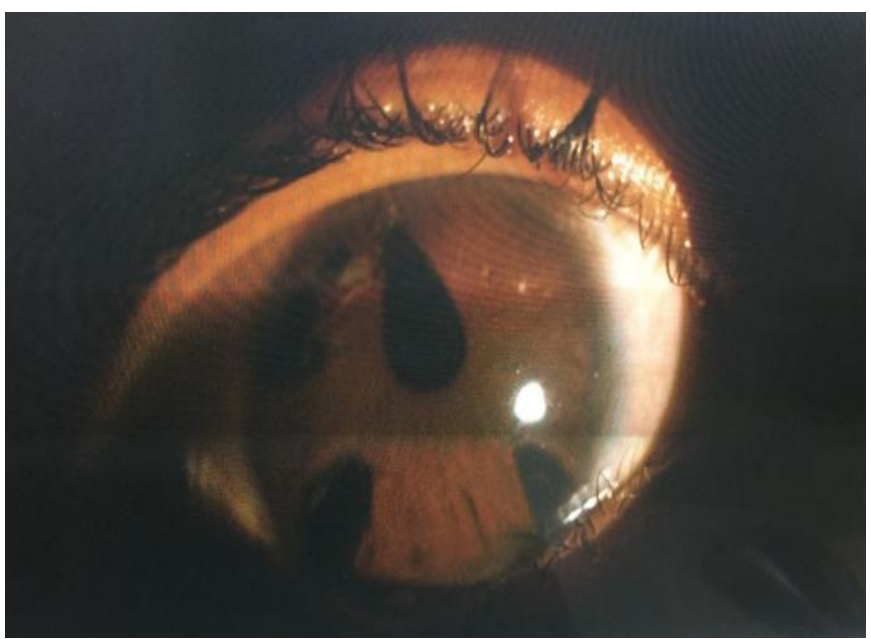

Figure 2 showing polycoria and correctopia 


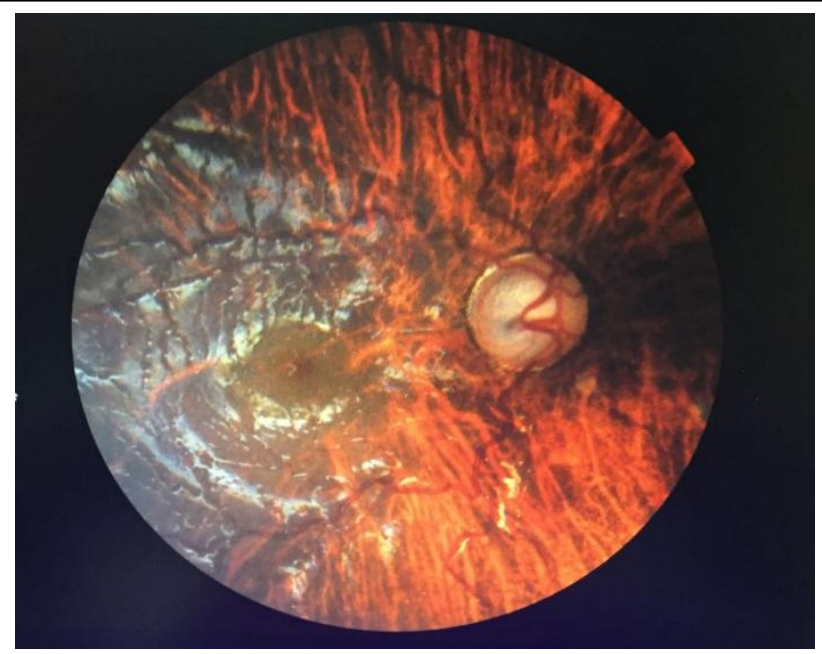

Figure 3 showing right eye vertical C:D ratio of 0.8 with tessellated fundus

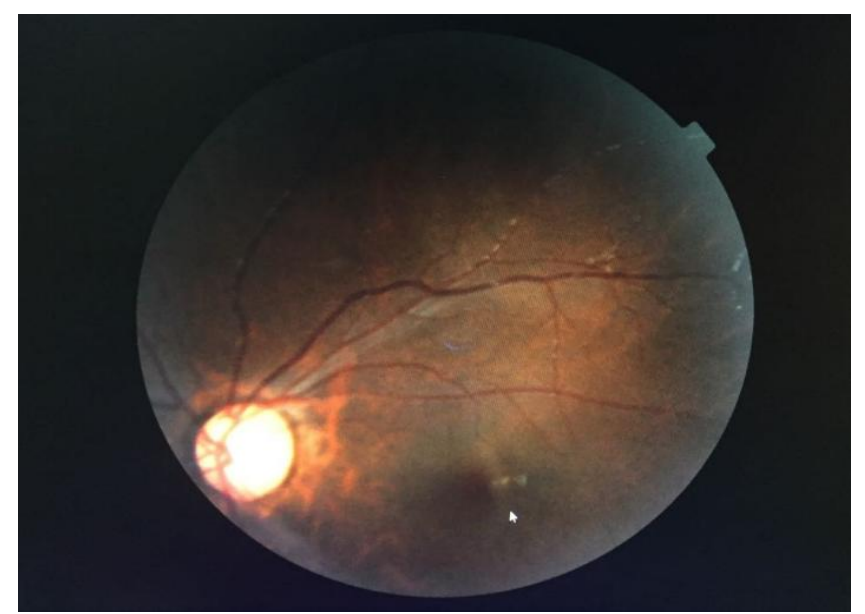

Figure showing left eye vertical C:D ratio 0.7

\section{Discussion}

Considering a $50 \%$ risk of development of glaucoma during childhood or early adulthood both eyes intraocular pressure was measured and was not elevated. Child being uncooperative hence gonioscopy could not be performed. The extraocular malformations which are also caused by abnormal neural crest cell related tissue development are suggestive of Rieger syndrome. His karyotyping showed no chromosomal abnormality. His two elder brothers did not have any significant complaints.

\section{Summary \& Conclusion}

A 11 year old male consulted in our department for watering and discharge from both eyes and diminution of vision since childhood. On general examination he had right sided head tilt, hypertelorism and flat nasal bridge. On ocular examination his visual acuity was finger count at $3 \mathrm{~m}$ in both eyes which did not improved with pin hole. Bitot spot was present in both eyes along with polycoria and corectopia in anterior segment. On fundus examination generalized tessellation was present in right eye and both eye had glaucomatous optic atrophy with vertical C:D ratio of 0.8- 0.9. He was diagnosed as a case of Axenfeld Reiger Syndrome with early onset glaucomatous optic atrophy. He was prescribed Intra ocular pressure lowering drugs and his pressures were well controlled on medication. Child is kept under follow up and visual acuity with intraocular pressure is assessed on each visit which needs to be lowered if elevated.

\section{Declaration of Patient Consent}

The authors certify that they have obtained all appropriate patient consent forms. In the consent form the patient has given his consent for his own pictures, fundus, and other clinical information to be reported in the journal.

\section{Financial Support: Nil}

Conflicts of Interest: There are no conflicts of interest.

\section{References}

1. Glaser T, Walton DS, Maas RL. Genomic structure, evolutionary conservation and aniridia mutations in the human PAX6 gene. Nat Genet. 1992;2(3):232-239.

2. Semina EV, Reiter R, Leysens NJ, et al. Cloning and characterization of a novel bicoid-related homeobox transcription factor gene, RIEG, involved in Rieger syndrome. Nat Genet. 1996; 14(4):392399.

3. Axenfeld TH. Embryotoxon cornea posterius. Klin Monatsbl Augenheilkd. 1920;65:381-382

4. Shields MB. Axenfeld-Rieger syndrome. A theory of mechanism and distinctions from the iridocorneal endothelial syndrome. Trans Am Ophthalmol Soc. $1983 ; 81: 736$ 
5. Shields MB. Axenfeld-Rieger and Iridocorneal Endothelial syndromes: Two spectra of Disease with Striking Similarities and Differences. $\mathrm{J}$ of Glaucoma. 2001;10(suppl 1):S36-S38. 